\title{
Frequency in Usage of Terminologia Anatomica Terms by Clinical Anatomists
}

\author{
Bradford D. Martin, ${ }^{1}$ Donna Thorpe, ${ }^{2,3}$ Vanessa DeLuna, ${ }^{4}$ Trish Howard, ${ }^{5}$ \\ Josh Hagemeyer, ${ }^{6}$ and Nicholas Wilkins ${ }^{7}$ \\ ${ }^{1}$ Department of Physical Therapy, School of Allied Health Professions, Loma Linda University, Loma Linda, CA 92350, USA \\ ${ }^{2}$ Institutional Research, School of Allied Health Professions, Loma Linda University, Loma Linda, CA 92350, USA \\ ${ }^{3}$ Department of Epidemiology and Biostatistics, School of Public Health, Loma Linda University, Loma Linda, CA 92350, USA \\ ${ }^{4}$ Department of Physical Therapy, White Memorial Medical Center, 1720 Cesar E. Chavez Avenue, Los Angeles, CA 90033, USA \\ ${ }^{5}$ Primary Therapy Source, 254 River Vista Place, Twin Falls, ID 83301, USA \\ ${ }^{6}$ Therapeutic Associates Gateway Physical Therapy, 2728 Pheasant Boulevard, Suite 100, Springfield, OR 97477, USA \\ ${ }^{7}$ Therapeutic Associates Hillsboro Physical Therapy, 5920 NE Ray Circle, Suite 160, Hillsboro, OR 97124, USA
}

Correspondence should be addressed to Bradford D. Martin; bdmartin@llu.edu

Received 29 May 2014; Accepted 25 August 2014; Published 18 September 2014

Academic Editor: Dragan Ilic

Copyright (C) 2014 Bradford D. Martin et al. This is an open access article distributed under the Creative Commons Attribution License, which permits unrestricted use, distribution, and reproduction in any medium, provided the original work is properly cited.

\begin{abstract}
Almost 16 years since the publishing of Terminologia Anatomica (TA) by the Federative Committee on Anatomical Terminology (FCAT), there has yet to be a unified adoption of TA-recommended anatomical terms by anatomists. A survey was sent to members of the American Association of Clinical Anatomists (AACA) to determine the frequency of TA term usage. Most respondents (70.3\%) received their terminal degrees in anatomy, with $23.4 \%$ in clinical and anthropological areas. Academically ranked, most respondents were professors (38.4\%) and most were from North America (81.1\%). Almost 40\% of respondents were textbook authors. Overall results indicate that the TA preferred term had the highest frequency of usage in only $53 \%$ of the anatomical structures/features surveyed. Compliance with TA preferred terms ranged from $98.2 \%$ to 3.6\% usage. Almost $25 \%$ of AACA anatomists were not familiar with the FCAT and over $75 \%$ were concerned about synonymity in anatomical terminology. Data demonstrates that clinical anatomists of the AACA are not consistent in how they use anatomical terminology, as well as how they conform to TA terminology.
\end{abstract}

\section{Introduction}

Human anatomy is a fundamental science that is important in all areas of medicine. Naming of body structures started around the 5th century BC, when Aristotle and Hippocrates initiated many new Greek anatomical terms [1]. Starting in the 1st century $\mathrm{AD}$, many more terms were added, until eventually there were 50,000 anatomical terms by the end of the 19th century, a majority derived from Latin [2]. Many of these new terms were introduced during the 17th to 19th centuries due to increased anatomical detail, but many synonyms, homonyms, and eponyms became prevalent during this period as well [3].

Since the 19th century, anatomical nomenclature has been the subject of considerable controversy and disagreement [4].
Many anatomists have called for a standardization of the vocabulary in anatomy, which would provide global agreement on naming structures. The International Federation of Associations of Anatomists (IFAA) commissioned the Federative Committee on Anatomical Terminology (FCAT, now referred to as FIPAT for Federative International Program for Anatomical Terminology) to publish Terminologia Anatomica (TA) [5] in response to international dissatisfaction on how anatomical terms were used $[3,4]$. The TA replaced the sixth edition of Nomina Anatomica (NA) published by the International Anatomical Nomenclature Committee (IANC) as the current authority for gross anatomical terms [6]. Ten years later, many anatomists and anatomy textbook authors had yet to adopt the FCAT terminology changes in TA $[7,8]$. This lack of compliance to TA approved terms has caused 
considerable confusion and discussion among anatomists, students, and clinicians over the validity of various anatomical terms $[1,3,7-13]$.

Many anatomists have pointed out imperfections that have contributed to lack of acceptance of TA. First, TA and other terminology systems have been criticized for not having considered linguistic aspects before forming a new standardized anatomical nomenclature $[7,14-16]$. The FCAT has been primarily concerned with including anatomical terms from all parts of the English-speaking world for democratic input, not just North America. This may have compromised the ability to apply linguistic or nomenclatural rationales consistently. Second, despite the fact that all anatomical nomenclatures produced so far have used Latin-based terminology [17], there appears to be a trend of avoiding Latin words from anatomical terms published in TA $[7,9]$. Also, TA was initially available only in Latin and English, which compromised its international acceptance, but now is available in several languages [13]. Third, the lack of distribution and dissemination of TA among anatomists and clinicians [12], difficulty with obtaining TA from the publisher [18], and lack of electronic databases [10-12] have all exacerbated the problem of TA awareness and adoption. To facilitate international usage in the literature, terminology needs to be easily accessible, preferably on the internet [1820].

Since English is currently the main language of communication, gaining a worldwide consensus concerning anatomical terms is an important task for future anatomists and clinicians [3]. Currently, anatomy textbooks and atlases are making considerable effort to follow TA, but variability still exists for many synonymic terms [12]. Also, North American anatomists are using anatomical terms in the classroom inconsistent with the recommendations of TA $[7,8]$.

Since academic anatomists have been studied $[7,8]$, we wanted to explore another group of instructors who have additional expertise in clinical practice. Anatomical terminology used in the clinic, although derived from the same root lexicon, does not comply with any universally adopted standard vocabulary such as TA. Historically, clinical anatomical terminology has evolved and diversified independently through localized usage in practice, research, and publication throughout the world [3]. In this study, we surveyed members from the American Association of Clinical Anatomists (AACA) to observe the influence of "clinical practice" on usage of anatomical terminology. Furthermore, the AACA is also a more international group, where many members are not from North America. Additional data and patterns on term usage will be beneficial to direct FIPAT in future versions of TA $[13,21,22]$.

\section{Methods}

An e-mail, with a link to an online survey, was sent in September 2008 to members of the American Association of Clinical Anatomists (AACA) who teach at the college or professional school level. The AACA had 666 members during the survey period. Excluded from the sample were student members, members without e-mail addresses, and adjunct faculty.
Only 477 members met the inclusion/exclusion criteria and were invited to participate in the survey. However, 50 emails returned as undeliverable, leaving 427 actual invited participants. Since some AACA members were also members of the American Association of Anatomists (AAA) or Human Anatomy \& Physiology Society (HAPS), it is possible that the AACA sample may have included a few respondents who participated in the previous studies [7, 8]. Although doubtful many would have performed the same survey twice, the maximum possible overlap between all three associations was $17.6 \%$.

The survey consisted of the same 25 sets of synonymic names for selected gross anatomical structures or related terms used in the AAA and HAPS surveys [7, 8]. These sets of terms were primarily identified in a review of 15 popular anatomy textbooks or atlases that are published for classroom usage [23-37]. Gray [23], Woodburne and Burkel [24], and Rosse and Gaddum-Rosse [25] were used for historical context.

The structures included are commonly referred to by two or more alternative names and therefore were considered "contentious" terms in relation to Terminologia Anatomica (TA). Participants selected the term or terms they use in the instruction of human anatomy courses or writing human anatomy textbooks from the sets of synonyms, including the recommended terms in TA. The TA preferred term was randomly placed in each set of alternative terms to not influence responses. Four questions had two TA acceptable terms included as answers: a TA preferred term and an older, well-established, secondary term. Respondents could select more than one synonym, if they utilized more than one term in their teaching. Alternative terms that were not present in survey questions were marked "Other." Due to the survey's design, respondents were unable to write in answers for the "Other" category.

The demographic portion of the survey included the following questions: how many years have you taught anatomy at a college or professional level? In what year did you receive your terminal degree? In what area is your terminal degree? What is your current academic rank? What region of the world do you teach or practice? Have you authored or been a contributing author to an anatomy textbook? How familiar are you with the FCAT? Are synonyms for anatomical structures a concern for you in teaching?

https://www.surveymonkey.com/ internet survey web service was utilized to administer the survey to all respondents [38]. A second e-mail reminder was sent on Day 13 for those who had not responded, and the survey was concluded for data analysis on Day 30. This survey study was determined to be exempt from the Loma Linda University Internal Review Board [45 CFR 46.101 (b)(2)].

Data Analysis. Frequencies and relative frequencies were used to summarize usage for TA and non-TA anatomical terms. For purpose of analysis, the secondary TA terms were categorized with non-TA terms. Quantitative variables were summarized with means and SDs. A Pearson chi-square analysis was used to test for an association between categorical variables; significance level accepted at $P<0.05$. IBM 
TABLE 1: Characteristics of AACA respondents $(n=111)$.

\begin{tabular}{lcc}
\hline & $N(\%)$ & Mean (SD) \\
\hline Years of teaching anatomy & & $23.3(12.4)$ \\
Year of terminal degree & & \\
Academic rank & & \\
Professor & $43(38.4)$ & \\
Associate professor & $35(31.3)$ & \\
Assistant professor & $22(19.6)$ & \\
Instructor & $3(2.7)$ \\
Emeritus or retired & $6(5.4)$ \\
Other & $3(2.7)$ \\
Geographic location & & \\
North America (96.7\% USA) & $90(81.1)$ \\
Europe & $7(6.3)$ \\
Asia & $6(5.4)$ \\
Middle East & $2(1.8)$ \\
Caribbean & $2(1.8)$ \\
South America & $1(0.9)$ \\
Other & $3(2.7)$ \\
Textbook author or contributor & $43(38.7)$ \\
\hline
\end{tabular}

SPSS Version 22.0 software was used for data analysis (IBM SPSS Statistics Documentation, Version 22.0 for Windows, Chicago, IL, 2013).

\section{Results}

At the end of the survey period, $26.0 \%$ of 427 invited AACA anatomists completed the survey (Table 1). Most of the AACA respondents were experienced professors and associate professors (Table 1) that had terminal degrees in anatomy (Figure 1). However, it is important to note that $23.4 \%$ of respondents had terminal degrees in medical professions (i.e., mostly in medicine, dentistry, physical therapy, and chiropractic, resp.). Most of the AACA respondents were from North America, with almost all of these from the USA. Collectively, $18.9 \%$ were international anatomists outside North America (Table 1). Also, many AACA respondents have authored or been a contributing author to an anatomy textbook (Table 1).

For the 111 respondents, $76.6 \%$ completed the 25 questions relating to anatomical terms. The number of questions skipped ranged from 1 to 8 per noncompleting respondent (mean $=2.6)$. A response of "Other" was selected by $40(36 \%)$ of the respondents from 1 to 3 times. Also, $84.7 \%$ of AACA respondents chose more than one term for a given question with only $15.3 \%$ of respondents never using more than one term per question.

Overall results indicate that the preferred TA term marginally predominated on 13/25 anatomical structures/ features (Figure 2; Table 2). When frequency of usage for all non-TA terms of a particular anatomical structure/feature is added together, the usage for non-TA terms marginally predominated on $14 / 25$ anatomical structures/features (Figure 2).

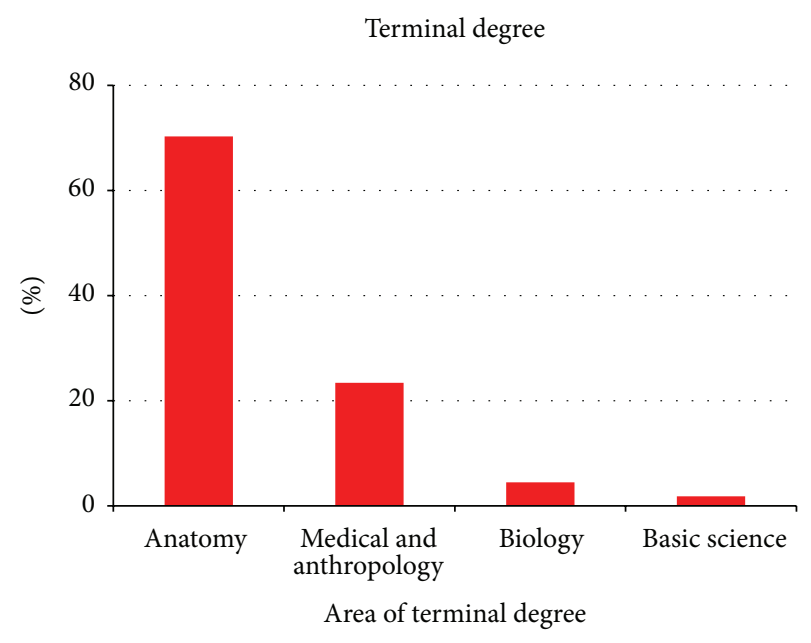

FIGURE 1: Areas in which AACA anatomists received their terminal degrees.

Responses from survey questions pertaining to anatomical term usage were categorized and analyzed according to linguistic, nomenclatural, or systematic problems in synonymic usage: (1) misnomers; (2) inconsistencies in term usage; (3) multiword sequencing; (4) oversimplification/Latin avoidance; and (5) spatial orientation in relation to anterior/posterior versus ventral/dorsal. Rationales for designation of terms into these various problem categories were thoroughly discussed previously [7]. As frequency of use for TA terms decreased by AACA anatomists, the corresponding frequency of use for non-TA terms increased for all five linguistic/nomenclatural/systematic problem categories (Figures 3, 4, 5, 6, and 7). Some questions showed almost complete compliance (highest $=98.2 \%$ usage) with the TA preferred terms to almost complete disregard (lowest $=3.6 \%$ usage) for the TA terms.

There were some interesting patterns for term preference for subcategories. For AACA anatomists who have taught for more than 20 years, there was a marginal significantly higher $(P=0.05)$ use of cubital fossa and calcaneofibular ligament, while there was a significantly lower $(P=0.04)$ use of flexor digiti minimi brevis, when compared to those with less teaching experience. Conversely, AACA anatomists with less than 20 years of teaching experience had a significantly higher use of patellar ligament $(P=0.01)$ than those with more teaching experience. Textbook authors of AACA used greater/lesser tubercles significantly more $(P=0.03)$ and intertubercular sulcus significantly more $(P=0.02)$ than the non-TA terms.

Internationally, AACA anatomists outside of North America used the hyphenated ary-epiglottic fold significantly more $(P<0.01)$ than North American AACA members. Conversely, North American AACA members used medial pterygoid and intertubercular sulcus significantly more $(P<$ 0.01) than international AACA anatomists.

FCAT Awareness and Concern about Synonymic Terms. Of the AACA survey respondents, $70 \%$ were not or not very familiar 


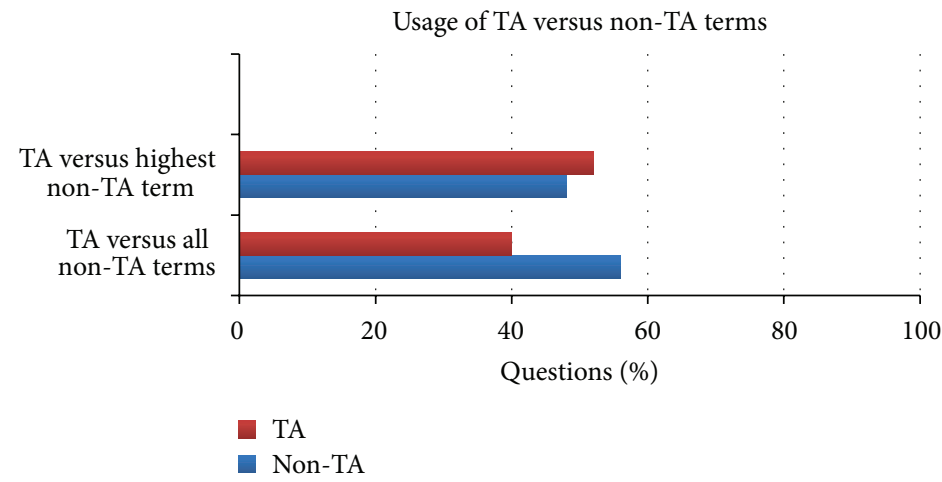

FIGURE 2: Usage (\%) of TA versus non-TA terms for 25 anatomical structures from survey questions sent to AACA anatomists.

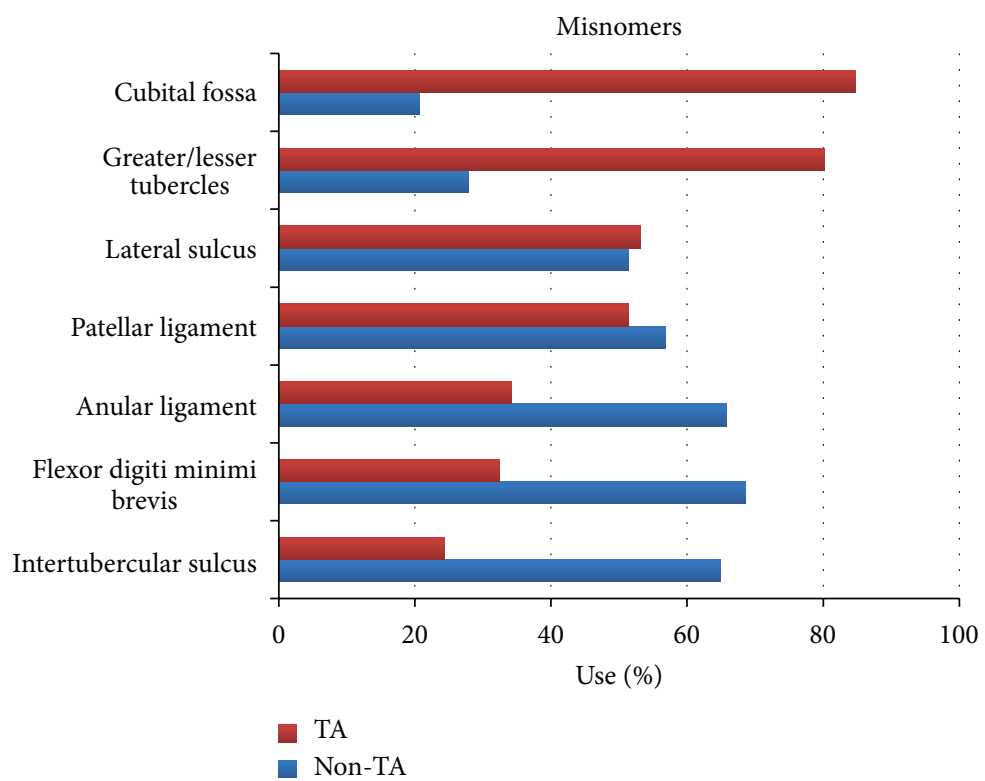

FIGURE 3: Percent use of the TA term and most frequently used non-TA term for each anatomical structure by AACA anatomists for various structures that represent misnomers. The structural names listed above are the TA preferred terms (see Table 2 for the highest non-TA term used for comparison above). Cumulative percentage for each structure is not $100 \%$ because all terms are not shown and more than one term could be selected by respondents.

with FCAT (Figure 8). Factors that were related to familiarity with FCAT included the respondents' terminal degree and authorship. Respondents with terminal degrees in anatomy were more familiar with FCAT than those with other degrees, and authors were more familiar with FCAT than nonauthors. Of the AACA respondents surveyed, 75.7\% were "somewhat concerned" or "definitely concerned" about synonymic terms in anatomy (Figure 9). There was no association between FCAT familiarity and concern for usage of synonymic terms.

\section{Discussion}

Results indicate that clinical anatomists from AACA do not follow the TA preferred terms in any consistent pattern. There was almost a consensus around the TA for some terms, while with other terms there was almost complete disregard. Many terms fell in between with partial compliance and partial disregard. The AACA respondents predominantly used nonTA terms more than the TA preferred terms, which is not surprising considering that $70 \%$ were not very familiar with FCAT. Despite this, over $75 \%$ of clinical anatomists were concerned with use of synonyms in anatomical terminology. The AACA respondents had more years of anatomy teaching experience than respondents in the AAA and HAPS studies $[7,8]$, which may explain why they were slightly more compliant and familiar with TA. Also, AACA anatomists are "academic clinicians," whereas "clinicians" are typically less aware and compliant with TA terms [10]. Unfortunately, we did not determine how many individuals with terminal degrees in anatomy (e.g., $\mathrm{PhD}$ or $\mathrm{DSc}$ ) also had a second clinical terminal degree (e.g., MD, DO, DC, DPT, or DDS).

No significant differences in anatomical term usage were detected between North American AACA anatomists and international AACA anatomists, except for higher usage 


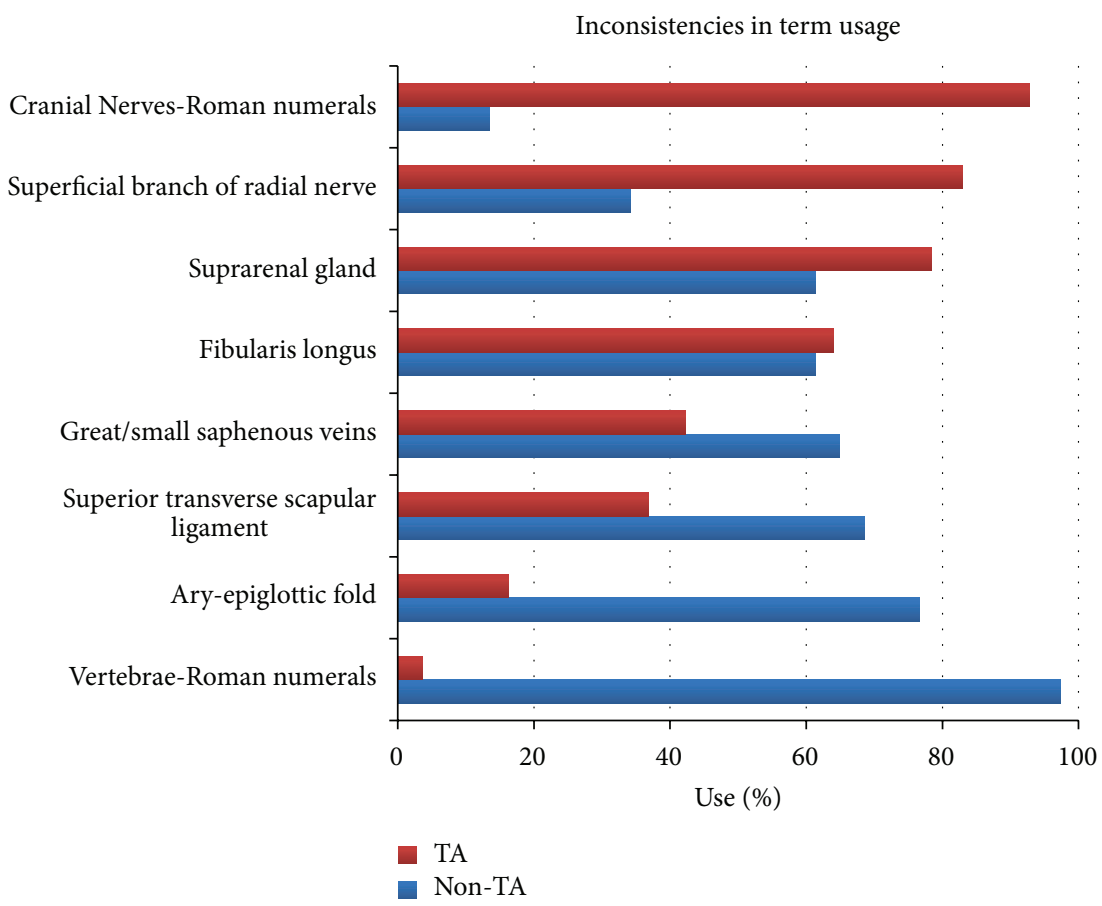

FIGURE 4: Percent use of the TA term and most frequently used non-TA term for each anatomical structure by AACA anatomists for various structures that represent inconsistencies in term usage. The structural names listed above are the TA preferred terms (see Table 2 for the highest non-TA term used for comparison above). Cumulative percentage for each structure is not $100 \%$ because all terms are not shown and more than one term could be selected by respondents.

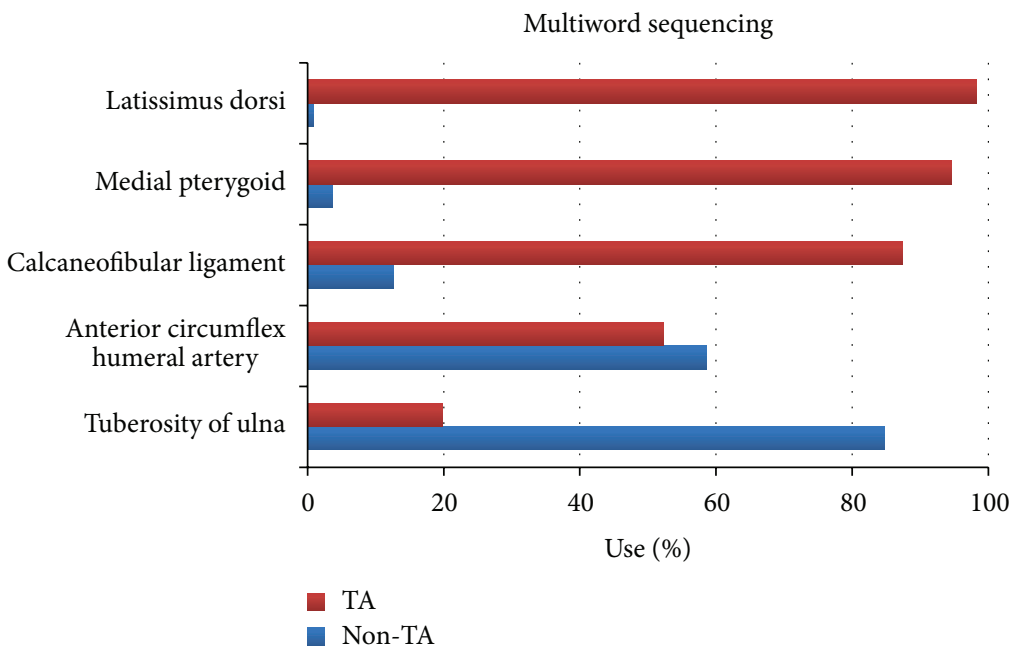

Figure 5: Percent use of the TA term and most frequently used non-TA term for each anatomical structure by AACA anatomists for various structures that represent multiword sequencing. The structural names listed above are the TA preferred terms (see Table 2 for the highest non-TA term used for comparison above). Cumulative percentage for each structure is not $100 \%$ because all terms are not shown and more than one term could be selected by respondents.

of hyphenated ary-epiglottic fold by international AACA anatomists, while North American AACA members used medial pterygoid and intertubercular sulcus more frequently than international AACA anatomists. This may possibly indicate a more traditional usage by international anatomists, as seen by higher preference of hyphenated names, pterygoid medialis, and bicipital groove.
A comprehensive and critical discussion on linguistic, nomenclatural, and systematic rationales of many TA terms that are inconsistent with the "unwritten rules" of anatomical terminology was previously published [7]. For example, greater and lesser tubercles of the humerus are actually tuberosities; "brevis" is not needed in flexor digiti minimi brevis (i.e., there is no "longus"); patellar ligament is really 


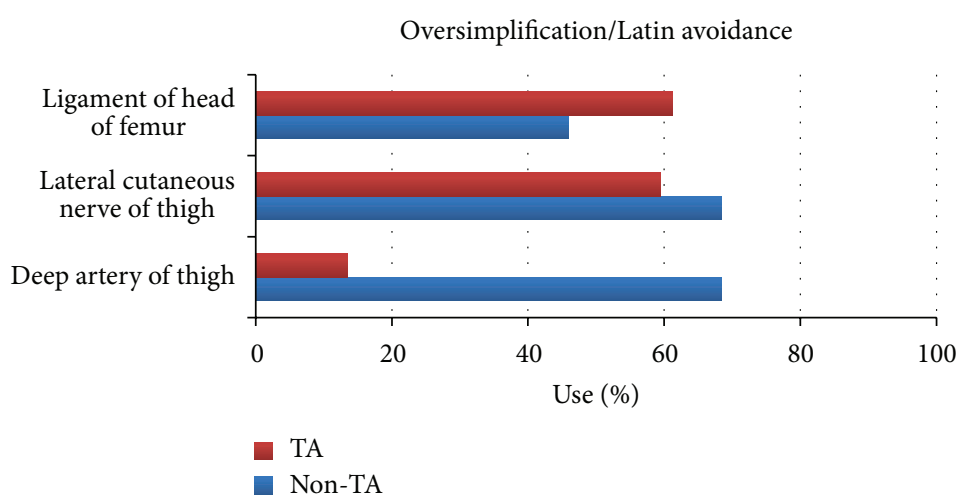

Figure 6: Percent use of the TA term and most frequently used non-TA term for each anatomical structure by AACA anatomists for various structures that represent oversimplification/Latin avoidance. The structural names listed above are the TA preferred terms (see Table 2 for the highest non-TA term used for comparison above). Cumulative percentage for each structure is not $100 \%$ because all terms are not shown and more than one term could be selected by respondents.

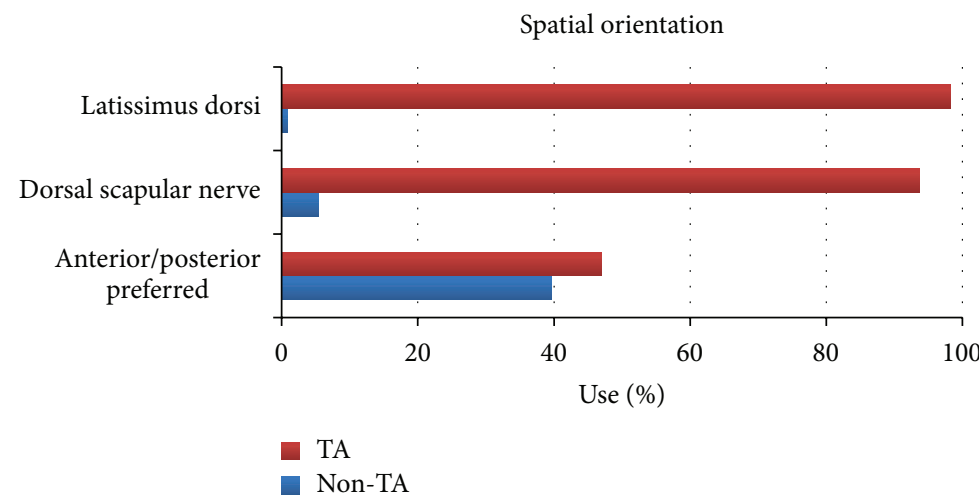

FIgURE 7: Percent use of the TA term and most frequently used non-TA term for each anatomical structure by AACA anatomists for various structures that represent spatial orientation. The structural names listed above are the TA preferred terms (see Table 2 for the highest non-TA term used for comparison above). Cumulative percentage for each structure is not $100 \%$ because all terms are not shown and more than one term could be selected by respondents.

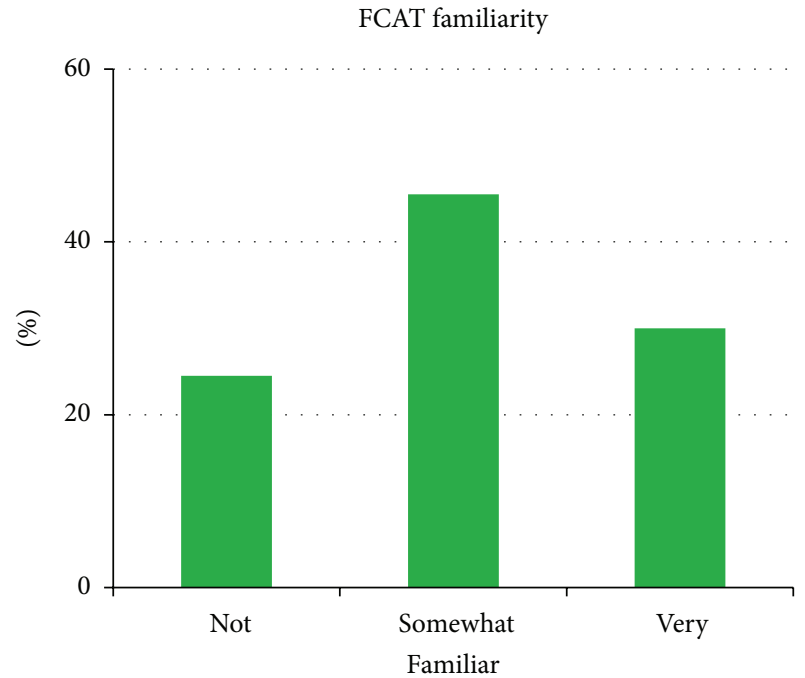

FIGURE 8: Familiarity of AACA anatomists with the FCAT.

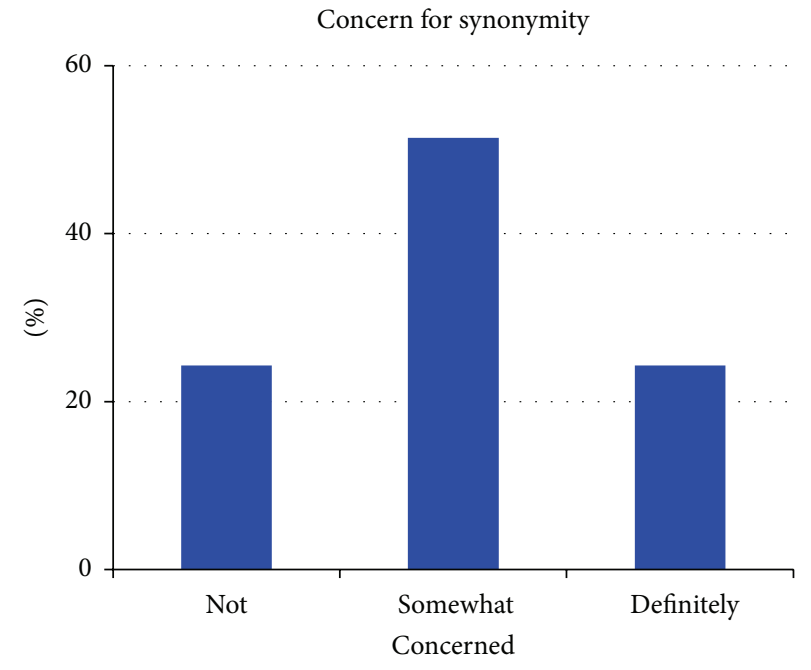

FIGURE 9: Concern of AACA anatomists in the usage of synonymic anatomical terms. 
TABLE 2: Frequency of usage for TA versus non-TA terms by AACA anatomists. Boldface names are the TA preferred terms. Values for $\%$ use are ranked from high to low for TA terms, while numbers in bold indicate the highest \% use for each set of terms $(n=111)$. Italicized names are acceptable TA terms, but secondary to the bold TA preferred term. "\% use" values do not add up to $100 \%$ for any particular question because the "other" category was not included and more than one term could be selected by respondents.

\begin{tabular}{|c|c|c|}
\hline \multirow[b]{2}{*}{ Synonymic anatomic terms } & \multicolumn{2}{|c|}{$\%$ use } \\
\hline & $\begin{array}{c}\text { TA } \\
\text { preferred } \\
\text { term }\end{array}$ & $\begin{array}{l}\text { Non-TA } \\
\text { preferred } \\
\text { term }\end{array}$ \\
\hline Latissimus dorsi & 98.2 & \\
\hline Dorsal latissimus & & 0.8 \\
\hline Latissimus posteri & & 0 \\
\hline Posterior latissimus & & 0 \\
\hline Medial pterygoid & 94.6 & \\
\hline Pterygoid medialis & & 3.6 \\
\hline Dorsal scapular nerve & 93.7 & \\
\hline Posterior scapular nerve & & 5.4 \\
\hline Cranial Nerves-Roman numerals & 92.8 & \\
\hline Cranial Nerves-Arabic numerals & & 13.5 \\
\hline Calcaneofibular ligament & 87.4 & \\
\hline Fibulocalcaneal ligament & & 12.6 \\
\hline Cubital fossa & 84.7 & \\
\hline Antecubital fossa & & 20.7 \\
\hline Superficial branch of radial nerve & 82.7 & \\
\hline Superficial radial nerve & & 34.2 \\
\hline Greater/lesser tubercles & 80.2 & \\
\hline Greater/lesser tuberosities & & 27.9 \\
\hline Suprarenal gland & 78.4 & \\
\hline Adrenal gland & & 68.3 \\
\hline Fibularis longus & 64.0 & \\
\hline Peroneus longus & & 61.3 \\
\hline Ligament of head of femur & 61.3 & \\
\hline Ligamentum teres & & 46.0 \\
\hline Ligamentum capitis & & 16.2 \\
\hline Lateral cutaneous nerve of thigh & 59.5 & \\
\hline Lateral femoral cutaneous nerve & & 68.5 \\
\hline Lateral sulcus & 53.2 & \\
\hline Lateral fissure & & 51.4 \\
\hline Lateral groove & & 1.8 \\
\hline $\begin{array}{l}\text { Anterior circumflex humeral } \\
\text { artery }\end{array}$ & 52.3 & \\
\hline $\begin{array}{l}\text { Anterior humeral circumflex } \\
\text { artery }\end{array}$ & & 58.6 \\
\hline Patellar ligament & 51.4 & \\
\hline Patellar tendon & & 56.8 \\
\hline Anterior/posterior preferably & 46.9 & \\
\hline $\begin{array}{l}\text { Ventral/dorsal \& } \\
\text { anterior/posterior }\end{array}$ & & 39.6 \\
\hline Ventral/dorsal preferably & & 19.8 \\
\hline Ventral/dorsal only & & 4.5 \\
\hline Anterior/posterior & & 3.6 \\
\hline
\end{tabular}

TABle 2: Continued.

\begin{tabular}{|c|c|c|}
\hline \multirow[b]{2}{*}{ Synonymic anatomic terms } & \multicolumn{2}{|c|}{$\%$ use } \\
\hline & $\begin{array}{c}\text { TA } \\
\text { preferred } \\
\text { term }\end{array}$ & $\begin{array}{c}\text { Non-TA } \\
\text { preferred } \\
\text { term }\end{array}$ \\
\hline Great/small saphenous veins & 42.3 & \\
\hline Greater/lesser saphenous veins & & 64.9 \\
\hline Long/short saphenous veins & & 7.2 \\
\hline $\begin{array}{l}\text { Superior transverse scapular } \\
\text { ligament }\end{array}$ & 36.8 & \\
\hline Suprascapular ligament & & 68.5 \\
\hline Anular ligament & 34.2 & \\
\hline Annular ligament & & 66.8 \\
\hline Flexor digiti minimi brevis & 32.4 & \\
\hline Flexor digiti minimi & & 68.5 \\
\hline Flexor digiti quinti & & 12.6 \\
\hline Intertubercular sulcus & 24.3 & \\
\hline Intertubercular groove & & 64.9 \\
\hline Bicipital groove & & 63.1 \\
\hline Intertuberosular groove & & 0.9 \\
\hline Tuberosity of ulna & 19.8 & \\
\hline Ulnar tuberosity & & 84.7 \\
\hline Ary-epiglottic fold & 16.2 & \\
\hline Aryepiglottic fold & & 76.6 \\
\hline Deep artery of thigh & 13.5 & \\
\hline Profunda femoris artery & & 68.5 \\
\hline Deep femoral artery & & 66.7 \\
\hline Vertebrae-Roman numerals & 3.6 & \\
\hline Vertebrae-Arabic numerals & & 97.3 \\
\hline
\end{tabular}

a tendon; cubital fossa is technically antecubital; the cerebral lateral sulcus is actually a fissure; great or small saphenous veins should be greater and lesser saphenous veins, like so many other contrasting names (e.g., greater and lesser trochanters); why hyphenate conjoint anatomical names ending and beginning with a vowel (e.g., ary-epiglottic fold)? calcaneofibular ligament violates the prevalent "proximal to distal" rule; use shorter names (e.g., ulnar tuberosity); deep artery of thigh has no Latin words to distinguish it as scientific; dorsal scapular nerve should be posterior scapular nerve, if ventral/dorsal are being phased out (e.g., posterior interosseous nerve), and why are some muscle names Latinized (e.g., latissimus dorsi), while others are Anglicized in word sequencing (e.g., medial pterygoid)?

Some TA preferred terms may be problematic for eventual compliance by clinicians and FIPAT may need to consider these before producing the next version of TA. For example, in order for suprarenal to replace adrenal gland, global changes will need to occur in a diversity of books/journals on physiology, pathology, pharmacology, and medicine, where they continue to refer to "adrenal insufficiency" or "adrenaline" (not "suprarenaline"), even though epinephrine should have replaced the latter term. Furthermore, anatomists and FIPAT need to realize that they cannot feasibly dictate what terms physiologists, pathologists, and clinicians use. Another problematic term is patellar 
ligament, where neurologists refer to the "patellar tendon reflex," not "patellar ligament reflex." Is not a sesamoid bone (i.e., patella) embedded in a tendon (not a ligament)? Beyond linguistic and systematic approaches, it would be wise for FIPAT to consider practicality in choosing preferred anatomical terms. Practicality would include a preference for shorter names, such as flexor digiti minimi (versus flexor digiti minimi brevis), ulnar tuberosity (versus tuberosity of ulna), aryepiglottic fold (versus ary-epiglottic fold), deep femoral artery (versus deep artery of thigh), and bicipital groove (versus intertubercular sulcus), which are five out of the six lowest TA compliance frequencies in the current study (Table 2). This abbreviating principle should also include acronymic names (e.g., LAD of the left coronary artery). It appears clinicians prefer shorter or more abbreviated names in order to quickly communicate in the clinic.

FCAT/FIPAT Awareness and TA Dissemination. Official FIPAT anatomical nomenclature should be available on the internet, where terminology can be quickly and easily accessed and updated $[10-12,18,19]$. Other ways to increase visibility and compliance with FIPAT terms include FIPAT presence at national and international anatomy meetings [12], requirement of FIPAT terminology by publishers and journals $[11,12]$, and strategic agreement by authors and clinicians in implementing a logical standardized terminology $[10,11]$.

In 2013, http://www.anatomicalterms.info/, a new website based at Leiden University Medical Center, The Netherlands, was launched to facilitate proper terminology usage and familiarity with TA [20]. One can quickly search for anatomical terms and see synonyms and eponyms in multiple languages, along with usage information by clinical specialty and geographic region of the world. There are various symbols used with these anatomical synonyms, including one that designates the TA preferred terms. A succinct definition of a concept is given for each term listed and images from Google are just a click away. Also, this site is "wikified," so that users can add terms if they are not already listed. The validity of additions to the site is reviewed and maintained by members of the Clinical Anatomical Terminology Committee of the AACA.

Despite all of the above strategies to increase FIPAT awareness, anatomists may still have difficulty reaching a consensus of one term per structure without consideration for linguistics and the development of written "nomenclature rules." We recommend that FIPAT create a formal anatomical nomenclature based on linguistics and practicality, not democratic input. This will promote logical and uniform application and ultimately make adoption and compliance easier for all anatomists and clinicians. Gest et al. [9] appear to agree that terminology should be kept simple, logical, and consistent. The FIPAT is open to revising TA terminology and the process is discussed in "Terminological desiderata" [21]. New terms always sound strange when using them for the first time, but ultimately we will grow familiar and accustomed to them. Once academic anatomists are convinced that FIPAT has formulated a systematic and linguistically unified terminology that considers practicality, medical clinicians should eventually follow in time.

\section{Conflict of Interests}

The authors declare that there is no conflict of interests regarding the publication of this paper.

\section{Acknowledgments}

Special thanks go to Dr. Arthur Kroetz for producing the figures in this paper. Also, thanks go to Shannon Greenlaw, PT, DPT, for help in the literature review and data collection.

\section{References}

[1] D. Kachlik, I. Bozdechova, P. Cech, V. Musil, and V. Baca, "Mistakes in the usage of anatomical terminology in clinical practice," Biomedical Papers of the Medical Faculty of the University Palacký, vol. 153, no. 2, pp. 157-162, 2009.

[2] T. D. Turmezei, "The linguistic roots of Modern English anatomical terminology," Clinical Anatomy, vol. 25, no. 8, pp. 10151022, 2012.

[3] D. Kachlik, V. Baca, I. Bozdechova, P. Cech, and V. Musil, "Anatomical terminology and nomenclature: past, present and highlights," Surgical and Radiologic Anatomy, vol. 30, no. 6, pp. 459-466, 2008.

[4] I. Whitmore, "Terminologia anatomica: new terminology for the new anatomist," Anatomical Record, vol. 257, no. 2, pp. 5053, 1999.

[5] FCAT, Terminologia Anatomica: International Anatomical Terminology, Thieme, Stuttgart, Germany, 1998.

[6] J. H. Dirckx, "Terminologia Anatomica: international anatomical terminology," Journal of the American Medical Association, vol. 283, no. 11, pp. 1485-1486, 2000.

[7] B. D. Martin, D. Thorpe, R. Barnes, M. DeLeon, and D. Hill, "Frequency in usage of FCAT-approved anatomical terms by North American anatomists," Anatomical Sciences Education, vol. 2, no. 3, pp. 94-106, 2009.

[8] B. D. Martin, D. Thorpe, V. Merenda, B. Finch, W. AndersonSmith, and Z. Consiglio-Lahti, "Comparison in usage of FCATapproved anatomical terminology between members of two anatomy associations in North America," Anatomical Sciences Education, vol. 3, no. 1, pp. 25-32, 2010.

[9] T. R. Gest, W. E. Burkel, and G. W. Cortright, "A need for logical and consistent anatomical nomenclature for cutaneous nerves of the limbs," Anatomical Sciences Education, vol. 2, no. 3, pp. $126-134,2009$.

[10] J. T. Laitman, "The Bible the flock will not follow," Anatomical Sciences Education, vol. 2, no. 3, pp. 137-138, 2009.

[11] W. Pawlina and R. Drake, "Moving forward with Terminologia Anatomica," Anatomical Sciences Education, vol. 2, no. 3, p. 93, 2009.

[12] A. W. Vogl, "Awareness of and access to a unified terminology by anatomists," Anatomical Sciences Education, vol. 2, no. 3, pp. 139-140, 2009.

[13] I. Whitmore, "Terminologia Anatomica includes terms in English for all scientists writing in English," Anatomical Sciences Education, vol. 2, no. 3, p. 141, 2009.

[14] E. Marečková, F. Šimon, and L. Červený, “On the new anatomical nomenclature," Annals of Anatomy, vol. 183, no. 3, pp. 201207, 2001. 
[15] G. Polackova, "Synonymy of medical terminology from the point of view of comparative linguistics," Bratislavské Lekárske Listy, vol. 102, no. 3, pp. 174-177, 2001.

[16] R. H. Baud, C. Lovis, A. M. Rassinoux, P. Ruch, and A. Geisbuhler, "Controlling the vocabulary for anatomy," in Proceedings of the AMIA Annual Symposium, vol. 2002, pp. 26-30, 2002.

[17] E. Marečková, F. Šimon, and L. Červený, "Latin as the language of medical terminology: some remarks on its role and prospects," Swiss Medical Weekly, vol. 132, no. 41-42, pp. 581-587, 2002.

[18] W. Pawlina and I. Maciejewska, "A00.0.00.101 Terminologia Anatomica et vox populi conveniant/let the Terminologia Anatomica and the voice of the people unite," Clinical Anatomy, vol. 16, no. 1, pp. 101-103, 2003.

[19] M. C. Manzanares-Céspedes, "On-line Terminologia Anatomica: a proposal," Anatomical Sciences Education, vol. 3, no. 3, pp. 154-155, 2010.

[20] O. P. Gobée, D. Jansma, and M. C. Deruiter, "AnatomicalTerms.info: heading for an online solution to the anatomical synonym problem hurdles in data-reuse from the Terminologia Anatomica and the foundational model of anatomy and potentials for future development," Clinical Anatomy, vol. 24, no. 7, pp. 817-830, 2011.

[21] C. Wendell-Smith, “Terminological desiderata," Clinical Anatomy, vol. 16, no. 1, pp. 98-99, 2003.

[22] P. Matusz, "Misleading Latin/English equivalents for some liver terms in Terminologia Anatomica," Anatomical Sciences Education, vol. 3, no. 3, pp. 156-157, 2010.

[23] H. Gray, Gray's Anatomy, Lea \& Febiger, Philadelphia, Pa, USA, 28th edition, 1966.

[24] R. T. Woodburne and W. E. Burkel, Essentials of Human Anatomy, Oxford University Press, Oxford, UK, 9th edition, 1994.

[25] C. Rosse and P. Gaddum-Rosse, Hollinshead's Textbook of Anatomy, Lippincott-Raven, Philadelphia, Pa, USA, 5th edition, 1997.

[26] S. Standring, Gray's Anatomy: The Anatomical Basis of Clinical Practice, Elsevier Churchill Livingstone, London, UK, 40th edition, 2008.

[27] P. W. Tank and T. R. Gest, Atlas of Anatomy, Lippincott Williams \& Wilkins, Baltimore, Md, USA, 1st edition, 2009.

[28] R. Drake, W. Vogl, and A. W. M. Mitchell, Gray's Anatomy for Students, Churchill Livingstone Elsevier, Philaelphia, Pa, USA, 2nd edition, 2010.

[29] K. H. Netter, Atlas of Human Anatomy, Saunders Elsevier, Piladelpia, Pa, USA, 5th edition, 2010.

[30] M. Schuenke, E. Schulte, and U. Schumacher, Thieme Atlas of Anatomy: General Anatomy and Musculoskeletal System, Thieme, Stuttgart, Germany, 1st edition, 2010.

[31] F. H. Martini, J. L. Nath, and E. F. Bartholomew, Fundamentals of Anatomy \& Physiology, Pearson Benjamin Cummings, San Francisco, Calif, USA, 9th edition, 2012.

[32] K. Saladin, Anatomy \& Physiology: The Unity of Form and Function, McGraw Hill, New York, NY, USA, 6th edition, 2012.

[33] R. Snell, Clinical Anatomy by Regions, Lippincott Williams \& Wilkins, Baltimore, Md, USA, 9th edition, 2012.

[34] E. N. Marieb and K. Hoehn, Human Anatomy \& Physiology, Pearson Benjamin Cummings, San Francisco, Calif, USA, 9th edition, 2013.
[35] K. P. Moses, J. C. Banks, P. B. Nava, and D. Petersen, Atlas of Clinical Gross Anatomy, Saunders Elsevier, Philaelphia, Pa, USA, 2nd edition, 2013.

[36] M. P. McKinley, V. D. O'Loughlin, and T. S. Bidle, Anatomy \& Physiology: An Integrative Approach, McGraw-Hill, New York, NY, USA, 3rd edition, 2013.

[37] K. L. Moore, A. F. Dalley, and A. M. R. Agur, Clinically Oriented Anatomy, Lippincott Williams \& Wilkins, Baltimore, Md, USA, 7th edition, 2014.

[38] SurveyMonkey, SurveyMonkey.com-Online-Based Survey Software, 2009, http://www.surveymonkey.com/. 

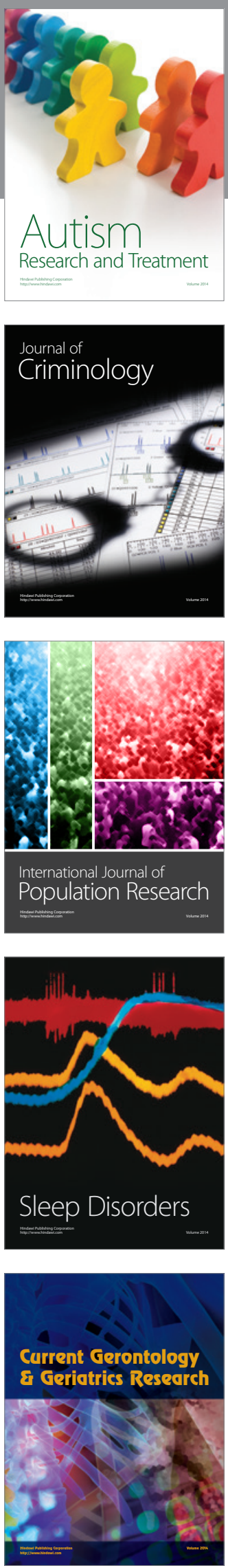
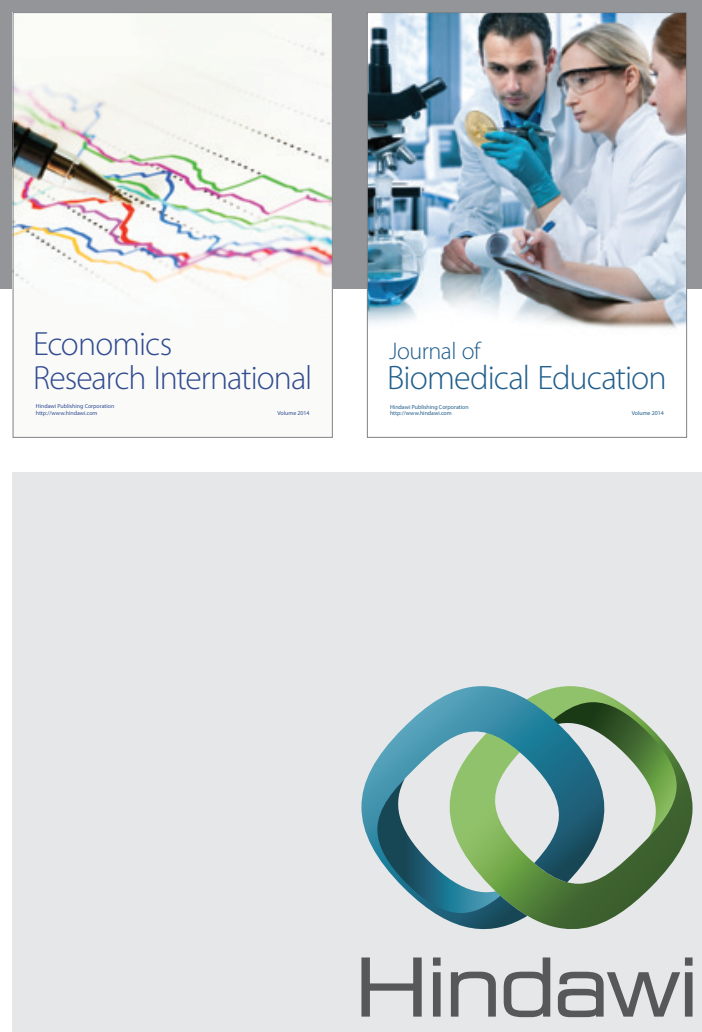

Submit your manuscripts at

http://www.hindawi.com
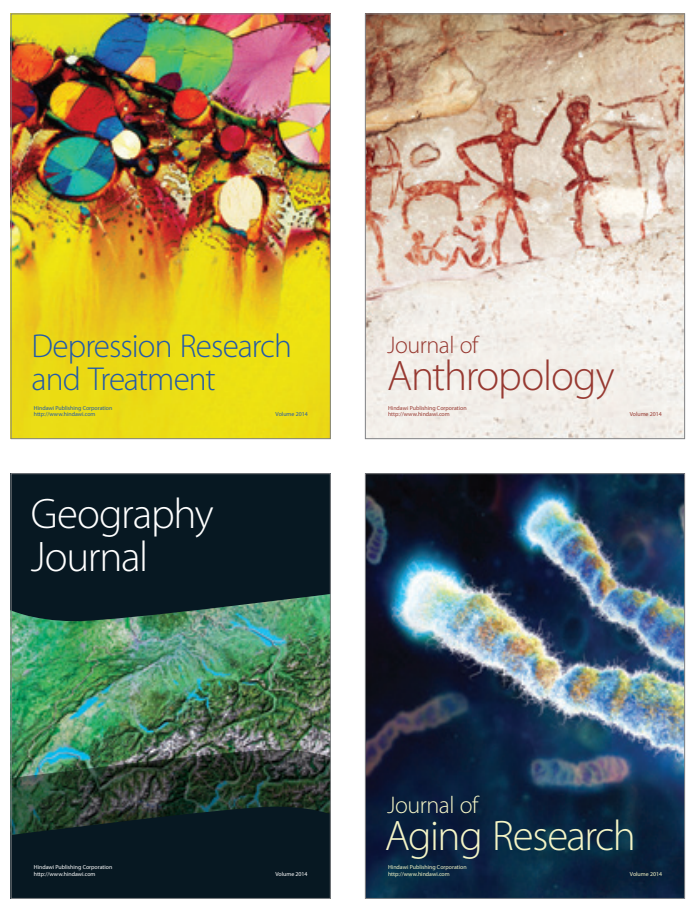
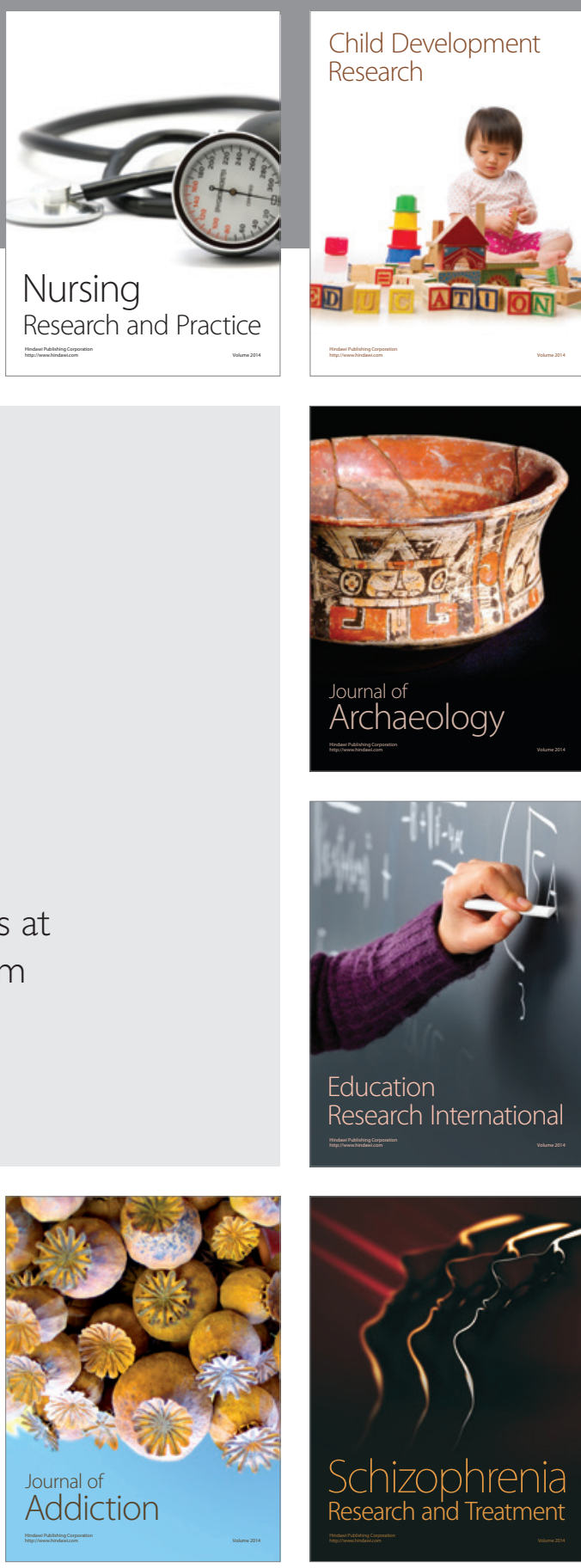

(D)
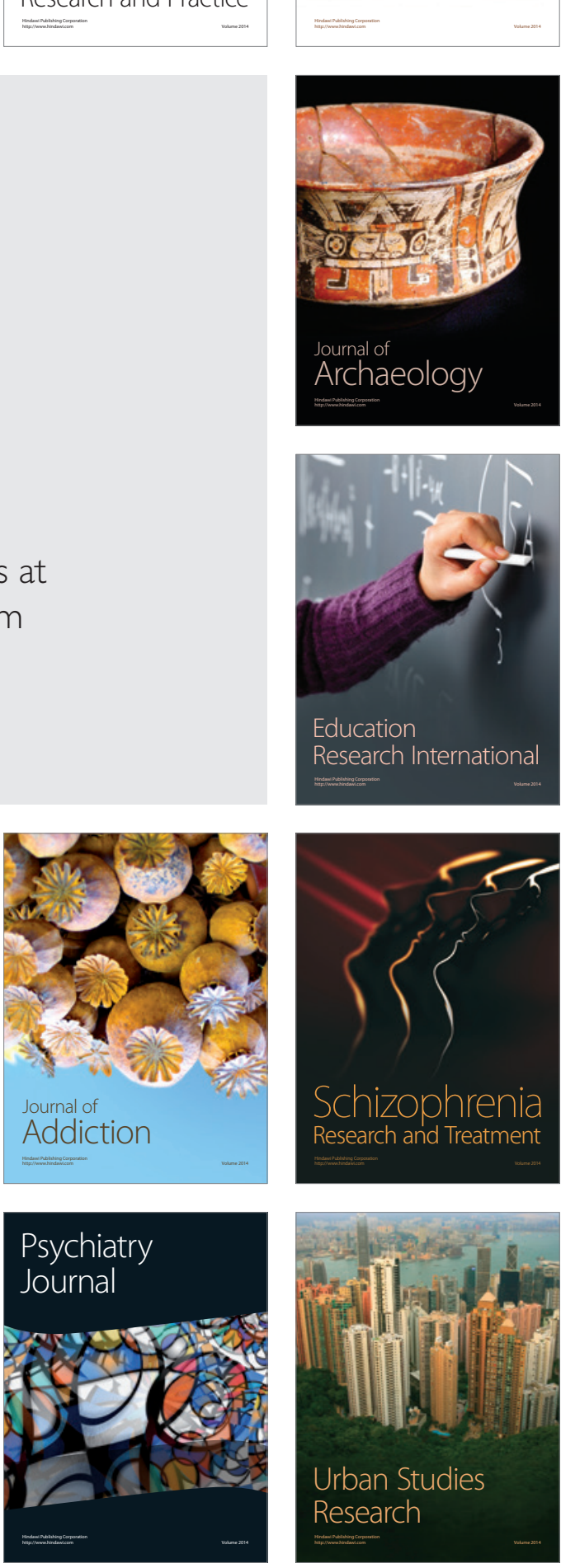